IKTISYAF: Bimbingan Penyuluahn Islam

Volume 2, Nomor 1, 2020 halaman 36 - 44

Sekolah Tinggi Ilmu Dakwah (STID) Sirrnarasa

\title{
METODE BIMBINGAN ROHANI BAGI PASIEN RAWAT TUBERKULOSIS
}

\author{
Didin Solehudin, Ridwan Farid \\ Bimbingan Penyuluhan Islam STID Sirnarasa
}

Didin@stidsirnarasa.ac.id

\begin{abstract}
ABSTRAK
Pasien yang diperlukan rawat inap di rumah sakit akan perlu seseorang yang dapat memberikan dorongan dan stimulus untuk mempercepat pemulihan. Selain untuk keluarga sebagai encourager, tentu saja, diperlukan personel terampil mampu menyediakan panduan, arah, dan saran-saran pasien. Penelitian ini bertujuan untuk mendeskripsikan program bimbingan rohani di RSUD $d r$. Soekardjo Tasikmalaya dan mendeskripsikan Layanan Bimbingan Rohani Islam bagi Pasien Rawat Inap Tuberkulosisi (TBC) di RSUD dr. Soekardjo Tasikmalaya serta Hasil dari Bimbingan Rohani itu sendiri berdasarkan analisis manajemen bimbingan dan konseling. Dimana program dan proses bimbingan rohani ini diperlukan dengan metode bimbingan rohani yang di terapkan untuk meningkatkan pelayanan terbaik bagi pasien dan sumber daya insani baik di lingkungan rumah sakit maupun di masyarakat. Rumah sakit RSUD dr. Soekardjo Tasikmalaya dijadikan sumber data untuk mendapatkan potret pelaksanaan bimbingan rohani Islam di rumah sakit. Dan metode yang dipakai dalam bimbingan rohani. Datanya diperoleh dengan cara wawancara bebas, observasi, dan studi dokumentasi. Seтua data dianalisis dengan pendekatan kualitatif dan analisis deskriptif Tuberkulosis (TBC) adalah penyakit menular langsung yang disebabkan oleh kuman (Mycobacterium tuberculosis) Kuman ini berbentuk batang, kuman tersebut biasanya masuk kedalam tubuh manusia melaliui udara yang di hirup kedalam paru, kemudian kuman tersebut dapat menyebar dari paru kebagian tubuh lain melalui sistem peredaran darah, sistem saluran limfa, melalui saluran pernapasan (broncus) atau penyebaran langsung ke bagian-bagian tubuh lainnya. Kajian ini menunjukkan bahwa Program Layanan Bimbingan Rohani Islam bagi Pasien Rawat Inap Tuberkulosis (TBC) di RSUD dr.Soekardjo Kota Tasikmalaya yaitu : Pembinaan mental spiritual bagi karyawan, Budaya Islami rumah sakit (Islamic Hospital Culture), Bimbingan rohani Islam bagi pasien, Dakwah Sosial, adapun prosesnya adalah : Memberikan masukan tentang agama, Memberikan motivasi, membantu melaksanakan ibadah wajib seperti shalat dan wudu. Sedangkan hasil dari pelaksanaan bimbingan adalah pasien yang di berikan bimbingan rohani lebih cepat kesembuhannya di bandingkan dengan pasien yang tidak di berikan bimbingan rohani.
\end{abstract}

Kata kunci: Bimbingan Rohani, Pasien Rawat Tuberkulosis

\section{ABSTRACT}

Patients who require hospitalization will need someone who can provide encouragement and stimulus to speed up recovery. In addition to family as encourager, of course, it requires skilled personnel capable of providing guidance, direction, and patient suggestions.This study aims to describe the spiritual guidance program at dr. Soekardjo Tasikmalaya and described the Islamic Spiritual Guidance Service for Inpatient Tuberculosis (TBC) at dr. Soekardjo Tasikmalaya and the results of Spiritual Guidance itself are based on management analysis of guidance and counseling. Where the spiritual guidance program and process is needed with spiritual guidance methods that are applied to improve the best service for patients and human resources both in the hospital environment and in the community. RSUD dr. Soekardjo Tasikmalaya was used as a source of data 
to get a portrait of the implementation of Islamic spiritual guidance in the hospital. And the methods used in spiritual guidance. The data is obtained by means of free interviews, observation, and documentation study. All data were analyzed using a qualitative approach and descriptive analysis.Tuberculosis (TB) is a direct infectious disease caused by germs (Mycobacterium tuberculosis) This germ is in the form of rods, these germs usually enter the human body through the air they breathe into the lungs, then these germs can spread from the lungs to other parts of the body through the circulatory system., the lymph system, through the respiratory tract (broncus) or spread directly to other parts of the body. This study shows that the Islamic Spiritual Guidance Service Program for Inpatient Tuberculosis (TBC) at RSUD Dr. Soekardjo, Tasikmalaya City, namely: Mental spiritual development for employees, Islamic Hospital Culture (Islamic Hospital Culture), Islamic spiritual guidance for patients, Social Da'wah, while the process is: Providing input on religion, Providing motivation, helping to carry out compulsory worship such as prayer and ablution. Meanwhile, the result of the implementation of guidance is that patients who are given spiritual guidance heal faster than patients who are not given spiritual guidance.

Keywords: Spiritual Guidance, Tuberculosis Care Patients

\section{PENDAHULUAN}

Tuberkulosis (TBC) adalah penyakit menular langsung yang disebabkan oleh kuman (Mycobacterium tuberculosis) dikemukakan pertama kali pada tahun 1982 oleh Robet Koch. Kemudian pada tahun 1944 di temukan streptomisin sebagai obat pertama anti Tuberkulosis (TBC). Penyakit Tuberkulosis (TBC) muncul kembali ke permukaan dengan meningkatnya kasus Tuberkulosis (TBC) di negara maju atau industri pada tahun 1990. Selain itu, peningkatan kasus Tuberkulosis (TBC) sebgai reemerging disease di pengaruhi pula dengan penyebaran infeksi HIV/AIDS. Saat ini di seluruh dunia terdapat 8 juta kasus terinfeksi dan 3 juta kasus meninggal.

Tuberkulosis (TBC) umumnya menyerang golongan usia produktif dan golongan sosial ekonomi rendah sehingga berdampak pada pemberdayaan sumber daya manusia yang dapat meghambat perumbuhan ekonomi negara.Penyakit Tuberkulosis (TBC) disebabkan oleh kuman Mycobacterium Tuberculosis. Kuman ini berbentuk batang, kuman tersebut biasanya masuk kedalam tubuh manusia melalui udara yang di hirup kedalam paru, kemudian kuman tersebut dapat menyebar dari paru kebagian tubuh lain melalui sistem peredaran darah, sistem saluran limfa, melalui saluran pernapasan (broncus) atau penyebaran langsung ke bagian-bagian tubuh lainnya.

Penyakit Tuberculosis (TBC) nampaknya masih banyak di derita oleh masyarakat, khususnya di Kota Tasikmalaya. Dalam hasil wawancara dengan ibu yuyun menyatakan bahwa dari data di rumah sakit penyakit Tuberkulosis menempati peringkat kedua dari data pasien yang meninggal di rumah sakit dr.soekardjo Kota Tasimalaya. Adapun data penyakit Tuberkulosis (TBC) yang penulis temukan di lapangan ketika melakukan observasi yaitu tepatnya di rumah sakit RSUD dr.soekardjo Kota Tasikmalaya yaitu bisa dikatakan banyak dilihat dari data dalam satu bulan. Dan juga menempati peringat kedua dalam kasus pasien yang meninggal di rumah sakit RSUD dr.Soekardjo Kota Tasikmalaya. Pasien yang memerlukan bantuan dorongan mental. Hal ini adalah sisi kebutuhan lain yang tidak boleh diabaikan. Pasien yang sakit selalu dihadapkan dengan perasaan, timbulnya goncangan dan mental jiwa mengenai penyakit yang dideritanya. Karena di rumah sakit RSUD dr.Soekardjo Kota Tasikmalaya khususnya penderita tuberkulosis banyak yang setres, tidak setabil psikologisnya (kejiwaan) karena penyakit yang di deritanya.

Stres ialah inteksi antara individu dan lingkungan yang ditandai dengan ketegangaan emosional berpengaruh dengan ketegangan mental, dan fisik seseorang. Stres merupakan salah satu penyakit psikis yang dapat berdampak pada fisik. Seperti yang penulis temukan dilapangan ketika 
dokter melakukan perawatan, atau misalkan ketika mau memakan obat tidak sedikit dokter mengalami kesusahan ketika menghadapi kejiwaan pasien Tuberkulosi (TBC) yang susah untuk melakukan penyembuhan. Oleh karena itu dengan adanya bimbingan seorang warohis (perawat rohani islam) yang dimana memiliki peran memberikan bimbingan doa bimbingan beribadah dan juga bimbingan motivasi kepada pasien penderita Tuberkulosi (TBC) ternyata memberikan efek yang baik dalam menunjang kesehatan pasien karena kondisi kejiwaan pasien Tuberkulosi (TBC) kondisi emosional atau prilaku pasien penderita penyakit Tuberkulosi (TBC) yaitu tidak banyak bicara (banyak diam), putus asa, mudah emosi, cenderung mengeluh, dan banyak yang mengganggu pasien lainnya. Oleh karena itu dalam penelitian ini penulis mengkaji teori konseling yang pas, yang baik yang harus di terapkan di rumah rumah sakit, dan yang penulis temukan ternyata teori yang di gunakan di rumah sakit adalah teori konseling psikoanalisa, adapun maksud dari teori psikoanalisa yang di kemukakan oleh Muhamad Surya dalam bukunya sebagai berikut.adapun yang penulis ketahui tentang konseling psikoanalisa yaitu yang pertama adalah tokoh utama dan pendiri psikoanalisa Tokohnya Sigmund Freud.

\section{LANDASAN TEORI}

\section{Definisi bimbingan rohani pada pasien tubekulosis}

Bimbingan secara harpiah terjemah dari kata guidance, yang berasal dari kata kerja "to guide" yang berarti menunjukan,memberi jalan atau menuntun orang lain ke arah tujuan yang lebih bermanfaat bagi hidupnya di masa kini dan masa yang akan datang.

Kata bimbingan dalam bahasa Indonesia memberikan dua pengertian yang mendasar, Pertama, memberi informasi, yaitu memberikan suatu pengetahuan yang dapat dimanfaatkan untuk mengambi keputusan, atau memberikan sesuatu dengan memberikan nasehat. Kedua, mengarahkan, menuntun ke suatu tujuan. Tujuan yang hanya diketahui oleh orang yang mengarahkan dan yang meminta arahan.

Kata rohani berasal dari kata roh atau ruh menurut toto tasmara, ruh adalah fitrah manusia yang dengan itu pula, manusia menjadi berbeda dengan binatang kekutan yang melangit dan bertanggung jawab, akan tetapi dapat juga melanggar berbagai norma-norma moral.

Bimbingan ditinjau dari segi bahasa atau etimologi berasal dari bahasa Inggris "guidance" atau "toguide", artinya menunjukkan, membimbing atau menuntun orang lain ke jalan yang benar. Rohani dari kata bahasa Arab روحانى yang mempunyai arti (mental). Dalam KBBI (Kamus Besar Bahasa Indonesia) disebutkan arti bimbingan adalah petunjuk (penjelasan) cara mengerjakan sesuatu, artinya menunjukkan, memberi jalan atau menuntun orang lain ke arah tujuan yang bermanfaat.

Bimbingan rohani Islam merupakan salah satu bentuk pelayanan yang diberikan kepada pasien untuk menuntun pasien agar mendapatkan keikhlasan, kesabaran dan ketenangan dalam menghadapi sakit. Bentuk pelayanan rohani ini bertujuan untuk meyakinkan pasien bahwa kesembuhan dan kesehatan adalah rahmat serta kekuasaan Allah swt. Layanan kesehatan di rumah sakit khususnya di Rumah Sakit Umum Daerah Kota Tasikmalaya perlu memberikan dua bentuk pelayanan: pertama, pelayanan aspek fisik yaitu perawatan dan pengobatan (medis). Kedua, pelayanan aspek non fisik yaitu rohani dalam bentuk santunan agama (spiritual). Kedua bentuk layanan tersebut harus dikerjakan secara terpadu (holistik) agar diperoleh hasil yang baik yaitu menolong dan membina manusia seutuhnya dengan fitrahnya

a). Definisi pasien Pasien Kata pasien berasal dari kata bahasa Indonesia analog dengan kata patient dari Bahasa Inggris. Patient diturunkan dari Bahasa latin yaitu patient yang memiliki kesamaan arti dengan kata kerja pati yang artinya menderita. Pasien adalah orang sakit, penderita 
(sakit), baik itu yang menjalani rawat inap pada suatu unit pelayanan kesehatan tersebut ataupun yang tidak, dan seseorang dikatakan sakit apabila orang itu tidak lagi mampu berfungsi secara wajar dalam kehidupan sehari-hari karena fisiknya yang sakit atau kejiwanya yang terganggu.

Adapun Beberapa definisi pasien menurut para ahli diantaranya : 1. Menurut Cristine Brooker dalam bukunya kamus saku Perawat; 2. Menurut Barbara F. Weller dalam buku kamus saku perawat pasien adalah orang sakit atau yang menjalani pengobatan karena menderita penyakit. Sedangkan rawat inap adalah opname, artinya pasien memperoleh pelayanan kesehatan menginap di Rumah Sakit.

b). Tuberkulosis (TBC) adalah penyakit menular langsung yang disebabkan oleh kuman (Mycobacterium tuberculosis) dikemukakan pertama kali pada tahun 19982 oleh Robet Koch. Kemudian pada tahun 1944 di temukan streptomisin sebagai obat pertama anti Tuberkulosis (TBC). Penyakit Tuberkulosis (TBC) muncul kembali ke permukaan dengan meningkatnya kasus Tuberkulosis (TBC) di negara maju atau industri pada tahun 1990. Selain itu, peningkatan kasus Tuberkulosis (TBC) sebgai reemerging disease di pengaruhhi pula dengan penyebaran infeksi HIV/AIDS. Saat ini di seluruh dunia terdapat 8 juta kasus terinfeksi dan 3 juta kasus meninggal.

Tuberkulosis (TBC) umumnya menyerang golongan usia produktif dan golongan sosial ekonomi rendah sehingga berdampak pada pemberdayaan sumber daya manusia yang dapat meghambat perumbuhan ekonomi negara.

Penyakit Tuberkulosis (TBC) disebabkan oleh kuman Mycobacterium tuberculosis. Kuman ini berbentuk batang, kuman tersebut biasanya masuk kedalam tubuh manusia melaliui udara yang di hirup kedalam paru, kemudian kuman tersebut dapat menyebar dari paru kebagian tubuh lain melalui sistem peredaran darah, sistem saluran limfa, melalui saluran pernapasan (broncus) atau penyebaran langsung ke bagian-bagian tubuh lainnya.

Tuberkulosis (TBC) paru pada manusia dapat di jumpai dalam dua bentuk, yaitu: pertama Tuberkulosis (TBC) paca primer yaitu bila penyakit timbul setelah beberapa waktu seseorang terkena infeksi dan sembuh. Tuberkulosis (TBC) ini merupakan bentuk yang paling sering di temukan. Dengan terdapatnya kuman dalam dahak, penderitaan merupakan sumer penularan. Kedua Tuberkulosis (TBC) primer yaitu bila penyakit terjadi pada infeksi pertama kali.

Bimbingan rohani Islam diperlukan sebuah dasar, karena dasar merupakan titik pijak dalam melangkah pada suatu tujuan. Bimbingan rohani Islam dilakukan oleh manusia dan kepada manusia. Oleh karena itu al-Qur'an dan hadist menganjurkan pada manusia agar memberikan bimbingan dan nasehat dengan wajar. Kedua hal tersebut merupakan sumber segala sumber pedoman hidup umat Islam, Al- Qur'an dan Sunnah Rasul dapat di istilahkan sebagai landasan ideal dan konseptual bimbingan rohani Islam.

Dari Al-Qur'an dan Sunnah Rasul itulah gagasan, tujuan dan konsep (pengertian makna hakiki) bimbingan rohani Islam bersumber. Hal ini sesuai dengan firman Allah dalam QS. AlImran ayat 104 : yang artinya: Dan hendaklah diantara kamu segolongan umat yang menyeru kepada kebajikan, menyuruh kepada yang ma'ruf dan mencegah dari yang mungkar, merekalah orang-orang yang beruntung" (QS. Alimran :104) Dari ayat tersebut dapat diketahui bahwa kita diwajibkan menyeru atau mengingatkan kepada kebaikan. Dan itu dapat kita lakukan melalui bimbingan rohani Islam atau bimbingan penyuluhan agama. Karena dengan agama dapat menuntun kita kearah jalan kebenaran sehingga kita akan meraih kebahagiaan di dunia dan diakhirat. Selain ayat di atas, anjuran untuk menjenguk orang sakit juga dianjurkan bagi kaum muslimin, seperti sabda Rasulullah : Dari Abu Hurairah rodhiyallahuanhu, ia berkata: Rasulullah shallallahualaihiwasallam bersabda: "Barangsiapa menjenguk orang sakit, atau mengunjungi saudaranya se Islam (karena Allah Swt), maka akan ada yang memanggilnya, bahwa engkau telah 
berbuat baik dan perjalananmu juga baik serta engkau telah menyiapkan suatu tempat tinggal di dalam Surga."

Pemberian bimbingan berarti tidak menentukan atau mengharuskan, melainkan sekedar membantu individu. Individu dibantu, dibimbing, agar mampu hidup selaras dengan ketentuan dan petunjuk Allah Swt. Tujuan bimbingan Islam yaitu untuk meningkatkan dan menumbuh seburkan kesabaran manusia tentang eksistensinya sebagai makhluk dan khalifah Allah Swt di muka bumi ini, sehinggah setiap aktifitas tingkah lakunya tidak keluar dari tujuan hidupnya yaitu untuk menyembah atau mengabdi kepa Allah Swt.

Pernyataan Salim yang menjelaskan bahwa tujuan bimbingan rohani Islam adalah memberikan ketenangan batin dan keteduhan hati kepada pasien dalam menghadapi penyakitnya, memberikan motivasi dan dorongan untuk tetap bertawakal dalam menghadapi ujian dari Allah Swt serta terpelihara keimanan ketakwaan pasien disaat menerima cobaan sakit.

\section{Materi Metode dan Bentuk Bimbingan Rohani Islam}

Adapun materi yang disampaikan dalam proses bimbingan rohani ini adalah :1. Akidah yaitu ketentuan-ketentuan dasar mengenai keimanan seorang muslim yang merupakan landasan dari segala prilakunya. 2. Syari'ah, yaitu ketentuan-ketentuan agama yang merupakan pengangan bagi manusia di dalam kehidupan untuk meningkatkan kualitas hidupnya dalam rangka mencapai kebahagian dunia dan akhirat. 3.Akhlak, yaitu adat, tabiat atau system prilaku yang dibuat. Secara bahasa bisa baik atau buruk tergantung pada tata nilai yang dipakai sebagai landasan.

Bimbingan rohani memiliki metode dan teknik.Metode dapat diartikan sebagai cara untuk mendekati masalah sehingga diperoleh hasil yang memuaskan sedangkan teknik merupakan penerapan metode dalam praktek. Terdapat dua metode bimbingan rohani Islam, yaitu metode langsung dan tidak langsung. Pertama Metode langsung adalah Metode langsung adalah metode di mana pembimbing melakukan komunikasi langsung dengan orang yang dibimbingnya. Metode ini dapat diperinci lagi yaitu secara individual dan kelompok. Metode individual dimana petugas rohani memberikan bimbingannya secara langsung kepada pasien satu persatu. Teknik yang digunakan adalah percakapan, kunjungan ke rumah pasien (home visit), dan observasi kerja. A. Metode individu ini dapat dilakukan dengan: 1. Percakapan pribadi yakni pembimbing melakukan dialog langsung tatap muka dengan pihak yang dibimbing. 2. Kunjungan ke rumah (home visit) yakni pembimbing melakukan dialog dengan pihak yang dibimbing tetapi dilaksanakan di rumah klien (orang yang dibimbing) sekaligus mengamati keadaan rumah dan lingkungannya. 3. Kunjungan dan observasi kerja yakni pembimbing melakukan percakapan individu sekaligus mengamati kerja klien dan lingkungannya.

Metode kelompok yaitu metode ini sama dengan (group guidance) hanya saja di sini pelaksanaan bimbingan petugas rohani mengarahkan pembicaraan dan diskusi pada masalah keagamaan dan sasarannya pada pasien yang mempunyai masalah yang sama. Pembimbing dalam melakukan komunikasi langsung dengan cara berkelompok. Petugas rohani melakukan bimbingan dengan pasien secara berkelompok, misalnya bimbingan yang dilakukan dengan cara memberikan materi tertentu (ceramah) kepada suatu kelompok. Pertama Metode tidak langsung Metode tidak langsung adalah cara yang digunakan petugas rohani melalui media komunikasi massa. Metode ini dapat dilakukan secara individu maupun kelompok. Pada metode individu, misalnya melalui telepon, surat menyurat, dan sebagainya, sedangkan pada metode kelompok, misalnya melalui buku, papan bimbingan, surat kabar atau majalah, brosur, radio (media audio), dan televisi. 
Dari metode bimbingan rohani di atas, dapat memberikan sebuah gambaran metode yang sangat tepat untuk, yang dapat digunakan oleh petugas rohani(warohis) dalam melakukan aktifitas bimbingan rohani di rumah sakit.sebagai penopang kesembuhan pasien Tuberkulosis (TBC).

Dari uraian diatas dapat disimpulkan bahwa metode bimbingan dibagi menjadi dua yaitu metode langsung adalah metode yang dilakukan di mana pembimbing (warohis) melakukan komunikasi langsung (bertatap muka dengan pasien). Metode tidak langsung adalah metode bimbingan yang dilakukan melalui media komunikasi massa. Dari metode di atas dapat memberikan gambaran tentang metode yang selayaknya digunakan oleh para warohis dalam melakukan bimbingan kepada para pasien di Rumah Sakit.

\section{METODE PENELITIAN}

Berdasarkan penelitian dan tujuan umum penelitian tentang "Metode Bimbingan Rohani Pada Pasien Rawat Inap Tuberkulosis (TBC) (Studi Kasus: di Rumah Sakit Umum Daerah Kota Tasikmalaya) adalah jenis penelitian kualitatif, yaitu penelitian yang menghasilkan data deskriptif berupa data-data tertulis atau lisan dari orang-orang atau perilaku yang dapat diamati.

Pendekatan yang digunakan adalah pendekatan religius. Pendekatan ini dapat diketahui keadaan keberagamaan pasien Tuberkulosis (TBC) dengan segala kesabaran yang ada pada dirinya sehingga diharapkan pasien dapat menerima sakit yang dideritanya dengan penuh keikhlasan. Pendekatan ini juga digunakan untuk menggambarkan suatu keadaan tingkat keagamaan pasien Tuberkulosis (TBC) dalam menangani kecemasan khususnya dan untuk mengetahui bagaimana pelaksanaan bimbingan rohani Islam yang diterapkan oleh Rumah Sakit Umum Daerah Kota Tasikmalaya.

\section{HASIL DAN PEMBAHASAN}

\section{A. Rumah Sakit dr. Soekardjo}

Rumah Sakit merupakan unit pelayanan kesehatan yang terdepan dan terdekat dengan masyarakat serta mempunyai tanggung jawab yang sangat besar atas kesehatan masyarakat yang ada disekitarnya serta di tuntut untuk memberikan pelayanan kesehatan yang bermutu yang dapat memenuhi kebutuhan pelayanan sesuai dengan standar (Quality of Compermance) sehingga secara tidak langsung dapat mempengaruhi derajat kesehatan masyarakat dengan kualitas pelayanan prima yang diberikan oleh Rumah Sakit. Rumah Sakit sebagai salah satu Badan Layanan Umum (BLU) merupakan ujung tombak dalam pembangunan kesehatan masyarakat. Namun tidak sedikit keluhan yang selama ini diarahkan pada kualitas pelayanan Rumah Sakit yang dinilai masih rendah terutama bagi rumah sakit daerah atau rumah sakit milik pemerintah.

Hal ini disebabkan karena masalah keterbatasan dana yang dimiliki oleh rumah sakit umum daerah atau rumah sakit milik pemerintah, sehingga dengan keterbatasannya itu tidak bisa mengembangkan mutu layanannya yang berdampak pada keterbatasan sarana dan prasarana yang tersedia serta keterbatasan kemampuan sumber daya masyarakat yang masih rendah. Namun dalam berjalannya waktu Rumah Sakit Umum Daerah dr. Soekardjo Kota Tasikmalaya berupaya untuk meningkatkan pelayanan kepada masyarakat sehingga dapat diketahui dengan adanya apresiasi positip dan meningkatnya tingkat kepuasan pelanggan dari tahun ke tahun dari masyarakat pengguna jasa rumah sakit melalui survey kepuasan pelanggan.

Adapun pelayanan yang diberikan oleh Rumah Sakit Umum Daerah dr. Soekardjo Kota Tasikmalaya adalah meliputi pelayanan gawat darurat 24 jam pelayanan rawat inap, pelayanan rawat jalan, pelayanan tindakan medis, pelayanan obat-obatan dan alat kesehatan, pelayanan penunjang diagnostik, pelayanan penunjang medis, pelayanan operasi dan pelayanan poliklinik. 


\section{B. Sejarah rumah sakit dr.Soekardjo}

Rumah Sakit Umum (RSUD) Tasikmalaya merupakan Rumah sakit Kelas B Non Pendidikan. Dahulu RSUD Kota Tasikmalaya disebut dengan "Provinciale Ziekenhuis" karena RSUD Kota Tasikmalaya pertama kali didirikan oleh Belanda pada tahun 1922 namun secara operasional RSUD Kota Tasikmalaya mulai beroperasi pada tanggal 14 Juli 1925. Adapun lokasi RSUD Kota Tasikmalaya pada jaman Belanda terletak di jalan Citapen komplek DPLAD (Detasemen Peralatan 03-12-03, Bengkel Lapangan B-03-44-8) di jalan Tentara Pelajar dan sejak mulainya operasional kemudian lokasi RSUD Kota Tasikmalaya dipindahkan ke jalan Rumah Sakit nomor 33 empangsari kecamatan tawang sampai dengan sekarang. Sejak berdirinya RSUD Kota Tasikmalaya sampai dengan tahun ini mengalami beberapa penggantian kepemimpinan.

\section{Layanan Bimbingan Rohani Islam RSUD dr.soekardjo Kota Tasikmalaya}

Bimbingan rohani Islam atau yang lebih di kenal bimrohis sejarah atau awal mula adanya warohis yaitu tanggal 09 oktober 2002 dengan jumlah 20 orang 18 laki-laki 2 perempuan. Adapun adanya bimrohis dengan bertujuan meningkatan religiusitas pasien yang berdampak pada kesembuhan dan motivasi pasien. RSUD dr.soekardjo tidak hanya mencapai kesembuhan pasien dengan bimbingan rohani, namun dilengkapi complementary medicine sebagai pelengkap pengobatan dan pelayanan medis, yaitu dakwah untuk menjaga dan memelihara keimanan pasien, serta pemenuhan bio-psiko-sociospiritual sebagai aspek kesehatan integral. Fungsi utama bimbingan rohani Islam di RSUD dr.soekardjo kota Tasikmalaya adalah pelayanan bagi pasien, bimbingan bagi karyawan, dan dakwah bagi masyarakat umum yang sedang menjenguk orang yang sakit.

Pasien khususnya penderita tuberkulosis (TBC) mengharapkan kehadiran bimbingan rohani Islam sebagai layanan supportive secara mental dan spiritual. Layanan bimbingan rohani Islam bagi pasien meliputi kunjungan pasien rawat inap, bimbingan pasien sakarotul-Maut, dan pelayanan pasien meninggal. Tujuan bimbingan rohani Islam adalah meningkatkan kualitas keimanan dan ketakwaan pasien, terwujudnya pelayanan islami secara terpadu yang terjangkau pada seluruh lapisan masyarakat, memberikan pengertian pada pasien agar dapat memahami tentang cobaan atau penyakit yang diderita dengan rasa ikhlas, dan menumbuhkan sifat dan sikap optimis kepada pasien bahwa penyakitnya dapat sembuh.

Bimbingan yang diberikan pada pasien penderita tubberkulosis (TBC) antara lain pasien selalu diingatkan waktu-waktu shalat, pasien dibantu untuk berwudlu jika mungkin untuk berwudlu dan dibantu dalam pelaksanaan shalat, pasien diingatkan agar selalu mengingat Allah Swt dan pasien dianjurkan untuk berdoa pada setiap waktu khususnya setelah melaksanakn shalat, dan ketika akan minum obat. Bagi pasien yang tidak sadarkan diri atau dalam kondisi terminal, pasien diarahkan untuk mempersiapkan diri dengan cara mendoakan, membimbing keluarganya, memberi motivasi keluarganya dan mengingatkan keluarganya supaya pasien terus di ingatkan kepada allah dan menuntun mengucapkan kalimat Allah semampunya, membacakan ayat suci al-Qur'an, dan pasien dihadapkan ke arah kiblat).

\section{Program Layanan Bimbingan Rohani Islam bagi Pasien Rawat Inap Tuberkulosis (TBC) di RSUD dr.Soekardjo Kota Tasikmalaya}

Bimbingan rohani Islam di RSUD dr.soekardjo Kota Tasikmalaya lebih dikenal dengan sebutan bimbingan rohani islam (BIMROHIS). Program kerja bimrohis terdiri dari empat program, yaitu pembinaan mental spiritual, konsep budaya rumah sakit peduli ibadah, bimbingan rohani pasien, dan dakwah sosial.

Keempat program tersebut memiliki kegiatan masing-masing yang meliputi: Pertama Pembinaan mental spiritual bagi karyawan, meliputi doa pagi yang dilaksanakan setiap hari dari 
mulai senin sampai minggu oleh petugas warohis sebelum memulai pekerjaan, di mulai dengan dimulai dengan merapihkan barisan oleh seorang warohis dimana petugas warohis merapihkan seluruh barisan setelah itu seorang warohis memulai upacara apel pagi biasanya ada dulu sambutan dari pihak direktur rumah sakit,setelah itu ketika selesai barulah seorang warohis memimpin doa dengan khidmat bersama seluruh karyawan rumah sakit. Ada juga dengan pengajian kultum di ruangan dengan mengikuti sesuai prosedur yang ada di rumah sakit. Dimulai dengan sambutan pagi terkadang tema kultum di ruangan rumah sakit suka ada yang rikues atau menanyakan suatu masalah dan biasanyah di jawab dengan pendekatan agama.

Kedua Budaya Islam RSUD dr.soekardjo Kota Tasikmalaya (Islamic Hospital Culture) meliputi penyusunan konsep budaya Islam, implementasi gerakan budaya yang disebut good governence, yaitu gerakan shalat berjama'ah. Biasanyah shalat berjamaah dimulai dengan warohis membaca shalawat menandakan bahwa waktu shalat sudah dekat, gerakan tepat waktu, biasa untuk mewujudkan shalat tepat waktu seorang warohis selalu menyiapkan siapa yang adzan iqomah dan imam, karena pernah dalam suatu kejadian karena biasanya sip sore atau malam petugas warohis hanya ada satu orang oleh karena itu, seorang warohis yang memiliki jadwal sip sore atau malam harus bertanggung jawab penuh setiap waktu shalat datang karena jika seorang warohis tidak adzan banyak pihak keluarga pasien maupun karyawan rumah sakit yang tidak shlat di masjid karena bingung siapa imamnya. gerakan menghormati majelis, dalam penerapannya biasanyah seorang warohis mengumumkan melalui pengeras suara supaya ketika sedang pengajian selalu di ingatkan supaya tidak bicara ketika shalat sedang berjalan ataupun pengajian.

\section{KESIMPULAN}

Pertama layanan bimbingan rohani di rumah sakit dr.Soekarjdo yaitu salah satunya adalah: Pembinaan mental spiritual yang pertama bagi karyawan rumah sakit. Program Budaya Islam RSUD dr.soekardjo Kota Tasikmalaya (Islamic Hospital Culture). Bimbingan rohani Islam bagi pasien. Dan dakwah Sosial.

Kedua Adapun dalam penerapan atau dalam Proses layanan bimbingan rohani islam pada Pasien Rawat Inap Tuberkulosis (TBC) di RSUD dr.Soekardjo Kota Tasikmalaya. Langkah awal, petugas rohani mendata pasien rawat inap melalui data pasien rawat inap di ruangan 6 yaitu ruang khusus pasien Tuberkulosis (TBC), selanjutnya perawat akan memberikan informasi yang dibutuhkan petugas rohani. Selanjutnya petugas rohani menanyakan perkembangan kondisi pasien. Selanjutnya membuat suasan suasana tercipta dengan baik antara warohis dan pasien..

Ketiga Adapun hasil dari bimbingan rohani yang dilaksanakan di rumah sakit dr. Soekardjo kota tasikmalaya yaitu berkurangnya tingkat kecemasan pada pasien, membuat pasien memiliki harapan penuh dan ketenangan lebih dengan adanya peran warohis atau dengan adanya bimbingan rohani islam dan semakin efektifnya pelaksanaan ikhtisar medis di ruangan 6 khusnya penderita penyakit tuberkulosis.

Berdasarkan penelitian dan analisisnya, maka dalam menumbuhkan motivasi hidup bagi pasien penderita Tuberkulosis (TBC) diperlukan layanan bimbingan rohani Islam secara intensif. Oleh sebab itu, penulis menyarankan sebagai berikut:

Pertama Bagi petugas rohani agar lebih meningkatkan layanan bimbingan rohani Islam dalam menumbuhkan motivasi hidup bagi pasien penderita Tuberkulosis (TBC) karena layanan bimbingan rohani Islam sangat bermanfaat bagi kesembuhan pasien dan menambah personil dengan tenaga professional agar pelayanan yang diberikan lebih maksimal.

Kedua Bagi dokter, paramedis, karyawan, dan seluruh jajaran direksi RSUD dr.soekardjo Kota Tasikmalaya, perlu memberikan dukungan penuh dan memahami tentang keadaan warohis lebih tepatnyah saling 
mendukung dengan satu tujuaan yaitu memberikan pelayan terbaik kepada pasien penderita Tuberkulosis (TBC).

\section{DAFTAR PUSTAKA}

Al-Mawardi, Hikmah Puasa Tinjauan Ilmu Kedokteran, (Jakarta: PT. Prima, 2001, Cet. Ke2).

Arifin, H.M. Pedoman Pelaksanaan Bimbingan Dan Penyuluh Agama.(Jakarta: Golden Tayaran Press. 1982).

Arifin, Pokok-pokok Bimbingan dan Penyuluhan Agama (Jakarta: Bulan Bintang, 1979).

Haris Herdiansyah, Wawancara, Observasi, dan Focus Groups,(Jakarta: PT Raja Grafindo Persada, 2013

Husaini Usman dan Purnomo Setiady, Metode Penelitian Sosial, (Jakarta: Bumi Aksara, 1996).

Jones J.J., Secondary School Administration, New York: (Mc Graw Hill Book Company, 1987).

Lexy JMoleong, Metodologi Penelitian Kualitatif, (Bandung: Remaja Rosdakarya, 2009).

Mellyartisyarif, Pelayanan Bimbing andan Penyuluhan Terhadap Pasien, (Jakarta: Kementrian Agama RI,2012).

Norman K. Denzin dan Yvonna S. Lincoln, Handbook Of Qualitative Research, (Yogyakarta: Pustaka Pelajar, 2009), Hal. 592

Noeng Muhadjir, Metodologi Penelitian Kualitatif, (Yogyakarta: Rake Sarasin, 1996).

Prayitno dan Amti, Dasar-dasar Bimbingan dan Konseling, (Jakarta: Rieneka Cipta, 1999).

Prastowo Andi, Metode Penelitian Kualitatif dalam Persepektif Rancangan Penelitian, (Yogjakarta: Ar-Ruzz Media, 2014).

Salim.Samsudin. Bimbingan Rohani Pasien Upaya Mensinergritaskan Layanan Medis dan Spiritual di Rumah Sakit. Winarno Surahmad, Pengantar Penelitian Ilmiah: dasar Metode Teknik, (Bandung: Tarsito, 1990).

Suharsimi Arikunto, Prosedur Penelitian Suatu Pendekatan Praktek, (Jakarta: Rineka Cipta,2002) 